\title{
Effect of moderate aerobic cycling on some systemic inflammatory markers in healthy active collegiate men
}

This article was published in the following Dove Press journal:

International Journal of General Medicine

21 January 20II

Number of times this article has been viewed

\author{
Ebrahim Akhtari Shojaei' \\ Adalat Farajov ${ }^{2}$ \\ Afshar Jafari ${ }^{3}$ \\ 'Tuberculosis and Lung Diseases \\ Research Centre, Tabriz University \\ of Medical Sciences, Tabriz, Iran; \\ ${ }^{2}$ Institute of Physiology, Baku National \\ Academy of Sciences, Baku, Azerbaijan; \\ ${ }^{3}$ Department of Sports Physiology, \\ Faculty of Physical Education and \\ Sports Sciences, University of Tabriz, \\ Tabriz, Iran
}

Background: Based on the inconsistency of some previous results related to moderate exercise effects on systemic inflammatory responses, this study was conducted to determine the effects of 45 minutes of moderate aerobic cycling on inflammatory markers, interleukin-6 (IL-6), interleukin-10 (IL-10), C-reactive protein (CRP), and leucocyte counts in young active men.

Methods: Ten healthy, active collegiate men (aged $21.03 \pm 1.2$ years, body fat $12.04 \pm 2.72 \%$ and $\mathrm{VO}_{2} \max 59.6 \pm 2.4 \mathrm{~mL} / \mathrm{kg} / \mathrm{min}$ ) in a quasiexperimental pre/post design, participated in an acute, moderate cycling protocol at an intensity of $50 \% \mathrm{VO}_{2} \max$ for 45 minutes. The inflammatory markers (serum IL-6, IL-10, CRP, and peripheral blood leucocyte counts), along with cortisol and epinephrine, were examined before and after the protocol. Data were expressed as mean $( \pm \mathrm{SD})$ and analyzed by paired $t$-test using SPSS15 at $\alpha \leq 0.05$.

Results: The results showed that serum IL-6, IL-10, CRP, total leukocyte counts, and stress hormones (epinephrine and cortisol) were significantly increased following 45 minutes of moderate cycling in active collegiate men $(P<0.001)$. However, all pre- and post-measurements were in the population range.

Conclusion: Based on the present results, it can be concluded that moderate cycling is not only sufficient to induce systemic inflammation in active collegiate men, but also appears to be safe from an immunological point of view.

Keywords: moderate cycling, pro- anti-inflammatory cytokines, C-reactive protein

\section{Introduction}

Chronic noncommunicable diseases (CNCD) such as cardiovascular conditions (mainly heart disease and stroke), some cancers, chronic respiratory conditions, and type 2 diabetes affect people of all nationalities and classes and are reaching epidemic proportions worldwide. Chronic disease accounts for approximately $60 \%$ of all deaths worldwide. ${ }^{1-7}$ On the other hand, inflammatory mechanisms have an important role in the pathological processes of chronic disease. ${ }^{7-18}$ This response is initially characterized by a local release of cytokines (eg, interleukin-6 [IL-6] and interleukin-10 [IL-10]), soluble polypeptides, and stress hormones (eg, cortisol and epinephrine) as modifying factors for the amplification and regulation of the inflammatory cascade. ${ }^{19-23}$ Cytokines are also involved in numerous physiological functions, such as muscle and bone tissue turnover, immunoregulation, and hematopoiesis ${ }^{22}$ and their circulating levels have been related to several disease processes, primarily atherosclerosis, cardiovascular disease, and all chronic noncommunicable diseases. ${ }^{4-18}$ Furthermore, physical training is effective in the
Correspondence: Afshar Jafari

$\mathrm{Tel}+994 \mathrm{II} 3393258$

Fax + 994113356008

Email akhtarie@tbzmed.ac.ir 
protection from and treatment of chronic disease. ${ }^{22-35}$ Public health physical activity recommendations state that moderate-intensity aerobic physical activity for a minimum of 30 minutes, at least 5 days each week, confers substantial protection against chronic diseases. ${ }^{27-30}$ Strenuously performed exercise may, however, cause harmful effects. ${ }^{23}$

Moderate exercise may have several beneficial effects for physical and psychological health and for immune system activity in both young and aged individuals. ${ }^{11}$ Some previous studies have shown that moderate-intensity exercise elicits changes in certain inflammatory markers. ${ }^{22}$ However, other studies have demonstrated that one bout of moderate exercise elicits no detectable change in the levels of various markers of inflammation. ${ }^{13,24,36-39}$ Several factors, including personal characteristics (eg, sex, age), history of exercise (active vs nonactive), and environmental conditions may affect results.

In view of these discrepancies in the data, the present study was conducted to determine the effect of a limited (45-minute) moderate aerobic exercise on inflammatory markers, IL-6, IL-10, acute-phase reactants (eg, C-reactive protein $[\mathrm{CRP}]$ ), and white blood cell count (WBC) in young, healthy active men.

\section{Methods}

\section{Subjects}

The subjects were 10 young active male students (aged $21.03 \pm 1.2$ years, body fat $12.04 \% \pm 2.72 \%$, and $\mathrm{VO}_{2} \max$ $59.6 \pm 2.4 \mathrm{~mL} / \mathrm{kg} / \mathrm{min}$ ) living at Tabriz University campus. Therefore, nutrition and other conditions were controlled. They had not participated in any heavy sport program in the previous 6 months. The exercise protocol was approved by the Ethics Committee of the Tabriz University of Medical Science. All participants were informed about the purpose and risks of the study before written informed consent was obtained. The exercise was carried out at the Department of Physiology, Tabriz University of Medical Science.

\section{Preliminary measurements}

One week before the study, health screening, anthropometric measurements, and maximal oxygen uptake were completed and determined in one session. Height, body weight, body mass index (BMI), and fat percent were determined by an experienced expert for both pre- and post-contest data. BMI was expressed as weight divided by height squared $\left(\mathrm{kg} / \mathrm{m}^{2}\right)$. Body fat percent was measured using a skin fold caliper (Eiken MK-60, Meikosha Co, Tokyo, Japan) and a standard protocol (ie, ASCM three-site suprailiac, abdomen, and triceps measured in millimeters):

$$
\begin{aligned}
\text { Body fat } \%= & (0.39287 \times \mathrm{SSF})-(0.00105 \times[\mathrm{SSF}] 2) \\
& +(0.15772 \times \text { age })-5.18845,
\end{aligned}
$$

where SSF $=$ sum of skin fold.

The incremental maximal cycle test (Astrand, 1965) was performed on a cycle ergometer (Ergo metrics 800S, SensorMedics, Yorba Linda, CA, USA). Participants started the test against an initial workload of $100 \mathrm{~W}$ and maintained a constant pedaling rate $(50 \mathrm{rpm})$ for the whole test. Every 2 minutes, the workload was increased by $50 \mathrm{~W}$ until the participants were unable to maintain the pedal rate at $50 \mathrm{rpm}$. During Astrand maximal test, the respiratory gas exchange analysis was continuously measured breath-by-breath using the computerized standard open circuit technique (SensorMedics Vmax 29, Yorba Linda, CA, USA). The gas analyzers were calibrated using standard gases of known oxygen and carbon dioxide concentration. Heart rate was measured with a heart rate monitor (Polar Electro, Kempele, Finland) and continuously supervised by a physician during all testing periods. Also, the rating of perceived exertion (RPE) was subjectively obtained by Borg scale in the final minute of the exercise protocol. ${ }^{40,41}$

\section{Experimental design and procedures}

Subjects were asked to refrain from exercise and did not take any anti-inflammatory medications for 72 hours before moderate aerobic cycling. However, 1 week after preliminary measuring, all subjects participated in an acute moderate cycling protocol at an intensity of $50 \% \mathrm{VO}_{2}$ max for 45 minutes. The exercise protocol was conducted in the laboratory where the temperature ranged between $22^{\circ} \mathrm{C}$ and $25^{\circ} \mathrm{C}$. The saddle height and handlebar positions of the ergometer cycle were adjusted to each subject's requirements and a short self-paced warm-up (5 minutes) was allowed. Each exercise and blood sampling was performed at the same time, between 9 and $10 \mathrm{AM}$, to protect against circadian fluctuation.

\section{Blood sampling}

Immediately before and after exercise, a blood sample $(7 \mathrm{~mL})$ was drawn from an antecubital vein. Immediately after collection, $1 \mathrm{~mL}$ of blood was sent for complete blood cell count $\mathrm{H} 1$ analysis and three $\mathrm{mL}$ were dispensed into tubes and left to clot at room temperature for 10 minutes in order to collect serum. Remaining blood samples were dispensed into EDTA-coated tubes and centrifuged for 10 minutes at $3000 \mathrm{~g}$ to collect plasma. The plasma and serum samples were stored 
at $-80^{\circ} \mathrm{C}$ until the day of assay. Plasma fasting blood glucose concentration was measured using an enzymatic reaction with glucose oxidase (Cobas Mira assay, Roche Diagnostic, Basel, Switzerland). Red blood cells (RBC), total and differential leukocyte count, as well as hemoglobin ( $\mathrm{Hgb})$ and hematocrit (Hct) levels were determined by automatic blood analyzer (Technicon H1, Technicon, Tarrytown, NY, USA).

\section{ELISA}

All measurements were performed using high sensitivity kits when available. This was the case for IL-6, IL-10 (Sanquin, Amsterdam, Netherlands), Hs-CRP (Pars Azmoon Co, Iran), epinephrine and cortisol (IBL, Hamburg, Germany).

The intra-assay variation for all enzyme-linked immunosorbent assay (ELISA) measurements was between 3\% and 7\%; detection limits for IL-6 $=0.2 \mathrm{pg} / \mathrm{mL}$ and for IL-10 $=0.1 \mathrm{pg} / \mathrm{mL}$. Leukocyte counts were adjusted for percentage changes in blood volume, whereas plasma and serum variables were adjusted according to percentage changes in plasma and blood volume, as calculated from Hgb and Hct. ${ }^{42}$

\section{Statistical analysis}

All data were defined as means $( \pm \mathrm{SD})$ and were first checked for normal distribution using one-sample KolmogorovSmirnov test and then statistical analyses were performed using the paired Student's $t$-test. Relationships between the parameters were examined with the Pearson's moment correlation test $(r)$. All statistical analyses were performed using the SPSS statistical software package (SPSS version 15.0 for Windows, SPSS Inc, Chicago, IL, USA). $P$ value $\leq 0.05$ was considered significant.

\section{Results}

Anthropometric and physiological characteristics of the study participants are described in Table 1.

$\mathrm{Hgb}$, total leukocyte count, neutrophil, lymphocyte, monocyte, and CRP were significantly increased after $45 \mathrm{~min}$ utes of moderate cycling in young active men (Table 2). However, Hct was not statistically different before and after moderate exercise $(47.34 \% \pm 2.03 \%$ vs $48.37 \% \pm 2.99 \%$,
Table 2). Following the cycling, the mean epinephrine, cortisol, IL-6, and IL-10 levels increased significantly $(P<0.001$, Table 3$)$. Figure 1 demonstrates the changes of stress hormones including epinephrine and cortisol before and after 45 minutes moderate cycling in these subjects. Table 3 shows the alterations in inflammatory markers (total leukocyte, CRP, IL-6, and IL-10) before and after 45 minutes moderate cycling in young active men.

Nevertheless, all resting and post-exercise serum CRP concentrations (acute-phase protein) were within the population reference range of $<3.0 \mathrm{mg} / \mathrm{L}$ and IL-6, IL-10 were in healthy individuals' range (according to manufacturer guidelines, $<20 \mathrm{pg} / \mathrm{mL}$ for IL- 6 and $<5 \mathrm{pg} / \mathrm{mL}$ for IL-10).

\section{Discussion}

In this study, we examined the influence of 45 minutes moderate aerobic cycling on blood concentrations of inflammatory markers and stress hormones in young healthy active men. Recent studies have shown that exercise type, individual fitness, duration, intensity, and history of exercise (active vs inactive) are important in determining the inflammatory response to exercise. ${ }^{13}$ Some previous studies have shown that moderate intensity exercise increases inflammatory markers, ${ }^{22}$ and others have found no effect. ${ }^{13,24,36-39}$ In the present investigation, we observed an inflammatory response following a 45-minute cycling protocol at $50 \% \mathrm{VO}_{2} \max$. Similar to this finding, Nieman and coworkers showed an increase in total leukocyte count and serum IL-6 concentration following a 30-minute treadmill walk at $60 \%-65 \% \mathrm{VO}_{2} \max$ in young women who walked regularly. ${ }^{27}$

Peake and coworkers, in contrast to our findings, investigated the effect of moderate-intensity exercise on serum concentrations of the anti-inflammatory cytokine IL-10, in young well-trained male runners and found no change after 60 minutes of running at $60 \% \mathrm{VO}_{2} \max .{ }^{24}$ It is not clear that differences in subject characteristics (ie, sex, age, fitness, history of exercise) and type of exercise (ie, cycling vs running) explain this discrepancy. Overall, these results suggest that physical activity may be associated

Table I Anthropometric and physiological characteristics of subjects $(n=10)$

\begin{tabular}{|c|c|c|c|c|c|c|c|}
\hline Variable & $\begin{array}{l}\text { Age } \\
\text { (years) }\end{array}$ & $\begin{array}{l}\text { Height } \\
(\mathrm{cm})\end{array}$ & $\begin{array}{l}\text { Weight } \\
\text { (kg) }\end{array}$ & $\begin{array}{l}\text { Body fat } \\
(\%)\end{array}$ & $\begin{array}{l}\text { BMI } \\
\left(\mathrm{kg} / \mathrm{m}^{2}\right)\end{array}$ & $\begin{array}{l}\text { VO } O_{2} \max \\
(\mathrm{mL} / \mathrm{kg} / \mathrm{min})\end{array}$ & $\begin{array}{l}\text { AT } \\
\left(\mathrm{VO}_{2} \mathrm{max} \%\right)\end{array}$ \\
\hline Mean & 21.3 & 175.6 & 64 & 12.04 & 20.8 & 59.6 & 0.53 \\
\hline SD & 1.2 & 6.2 & 4.8 & 2.72 & 1.6 & 2.4 & 0.09 \\
\hline
\end{tabular}

Abbreviations: BMI, body mass index; AT, anaerobic threshold; SD, standard deviation. 
Table 2 Comparison of blood indices after 45 minutes of acute moderate exercise in young active men $(n=10)$

\begin{tabular}{lllll}
\hline Variable & Stage & Mean & SD & P value \\
\hline Total leukocytes & Pre-exercise & 5.747 & 0.47 & $<0.01$ \\
$\left(\times 10^{\circ} / \mathrm{L}\right)$ & Post-exercise & 6.6 & 0.45 & \\
Neutrophil & Pre-exercise & 3.015 & 0.123 & 0.035 \\
$\left(\times 10^{\circ} / \mathrm{L}\right)$ & Post-exercise & 3.462 & 0.555 & \\
Lymphocyte & Pre-exercise & 2.246 & 0.35 & 0.028 \\
$\left(\times 10^{\circ} / \mathrm{L}\right)$ & Post-exercise & 2.51 & 0.326 & \\
Monocyte & Pre-exercise & 0.383 & 0.065 & 0.030 \\
$\left(\times 10^{\circ} / \mathrm{L}\right)$ & Post-exercise & 0.421 & 0.691 & \\
\hline
\end{tabular}

Note: Blood indices significantly increased after 45 minutes moderate cycling in young active men.

Abbreviation: SD, standard deviation.

with lower levels of systemic inflammation among healthy adults. $^{2-7}$ Public health physical activity recommendations state that moderate-intensity aerobic physical activity for a minimum of 30 minutes for at least 5 days each week confers substantial protection against chronic diseases, such as cardiovascular disease..$^{5,9}$

In contrast to our findings, Markovich and coworkers showed that a single bout of running at $50 \% \mathrm{VO}_{2} \max$ for 30 minutes did not cause change in various markers of inflammation (pro- and anti-inflammatory) in middle-aged sedentary men. ${ }^{13}$ Variances in results are perhaps due to differences in type of exercise (cycling vs running), individual fitness (trained vs sedentary), or personal characteristics, such as age (young vs middle age).

Scharhag showed 3.5-4.5-fold increases in CRP concentrations $16-24$ hours post-exercise. ${ }^{22}$ We observed only a small, though significant, increase in serum CRP concentration immediately after exercise and other studies have reported a small decrease in CRP concentrations 24 hours post-exercise. ${ }^{43}$ These discrepancies could be due to

Table 3 Comparison of serum concentrations of inflammatory markers before and after 45 minutes moderate cycling in young active men $(n=10)$

\begin{tabular}{lllll}
\hline Variables & Stage & Mean & SD & P value \\
\hline IL-6 & Pre-exercise & 1.157 & 0.07 & $<0.0$ I \\
$(\mathrm{pg} / \mathrm{mL})$ & Post-exercise & 1.578 & 0.12 & \\
IL-I 0 & Pre-exercise & 2.367 & 0.133 & $<0.0$ I \\
$(\mathrm{pg} / \mathrm{mL})$ & Post-exercise & 2.992 & $0.23 \mathrm{I}$ & \\
$\mathbf{C R P}$ & Pre-exercise & 0.45 & 0.23 & $<0.0 \mathrm{I}$ \\
$(\mathrm{mg} / \mathrm{L})$ & Post-exercise & 0.69 & 0.14 & \\
Blood sugar & Pre-exercise & 77 & 9.39 & $<0.0 \mathrm{I}$ \\
$(\mathrm{mg} / \mathrm{dL})$ & Post-exercise & 73.5 & 10.44 & \\
\hline
\end{tabular}

Note: Serum concentrations of IL-6, IL-10, and CRP significantly increased after 45 minutes of moderate exercise in young active men.

Abbreviations: IL, interleukin; CRP, C-reactive protein; SD, standard deviation. differences in the sampling periods and lag of CRP appearance in circulation after different exercise intensities.

Furthermore, the different methods used to measure serum cytokine concentrations in these studies, such as flow cytometry or cytometric bead array are not sensitive enough to detect relatively minor changes in levels after various types of exercise. In contrast, ELISA is sensitive enough to detect low concentration changes of human cytokines after different exercises. ${ }^{44}$

Whereas, it appears that moderate-intensity exercise increases circulating pro- and anti-inflammatory markers in young active men who are accustomed to exercise and that some kind of intensity or duration threshold must be achieved to elicit an acute change in measures of IL-6, IL-10, and other inflammatory indices. Other studies have shown that exercise of a shorter or similar duration does not elicit an inflammatory response, but only if the intensity is higher. ${ }^{36,43}$ Similarly, low-intensity protocols that are prolonged in duration ( 5 hours at $40 \% \mathrm{VO}_{2} \max$ ) also induce an inflammatory response. ${ }^{35}$ It is also noteworthy that studies that employ more intense exercise protocols tend to use younger and fitter individuals and this means that not only is there a difference in terms of relative work rate (ie, $50 \%$ vs $60 \% \mathrm{VO}_{2} \max$ ), but there will be an even more pronounced difference in absolute work rate because of an age-related decline in capacity (eg, in absolute running speeds).

Although inflammatory markers were increased after moderate exercise, all pre- and post- exercise values were within normal range and not harmful to subjects' health from clinical point of view.

These findings suggest that anti-inflammatory and antiatherogenic effects of regular moderate-intensity physical activity must be explained by something other than a transient net anti-inflammatory response to each exercise bout and may be explained by other changes that accumulate when exercise is performed over weeks and months.

In view of the controversies in this field, it may have been interesting to measure the inflammatory marker levels at different times after the cessation of the exercise bout $(0,1$, 2,5 , and 24 hours, for example) to determine whether the changes observed were transient or sustained. No functional test of kinetic and subpopulation of leukocytes, along with serial measurements in the time period after exercise, were performed. A further investigation looking at different intensities and durations of exercise on the immediate changes in these parameters would seem worthwhile. 

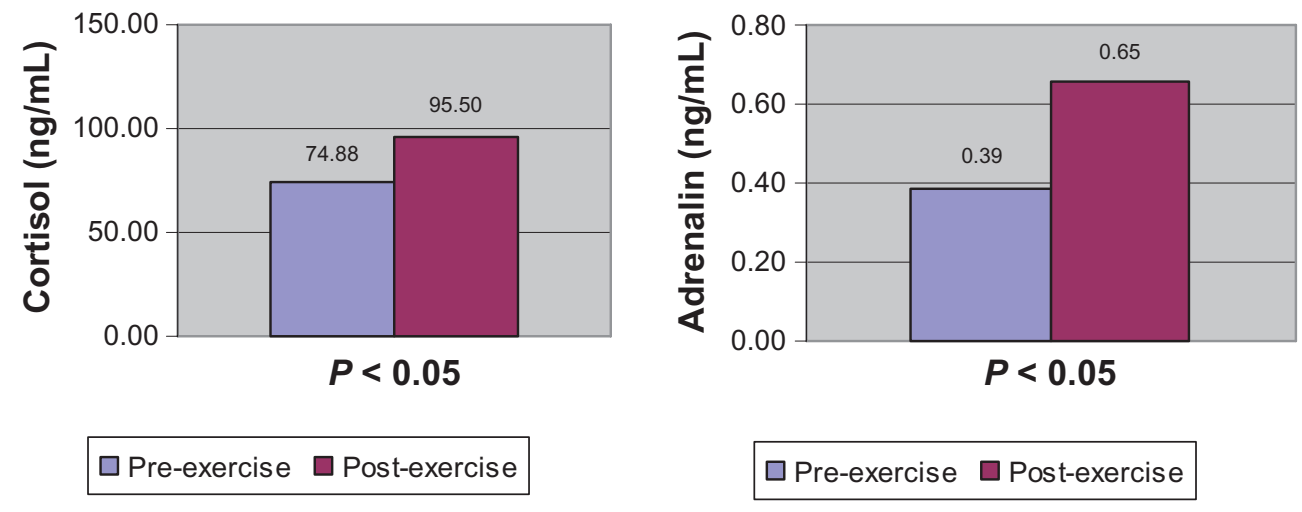

Pre-exercise $\square$ Post-exercise

Figure I Comparison of stress hormone (cortisol, epinephrine) changes before and after 45 minutes of moderate cycling in young active men.

\section{Conclusion}

Cycling at a moderate intensity for 45 minutes increased systemic markers of inflammation (WBC, serum IL-6, IL-10, and CRP concentrations) and stress hormones, but this increase has no clinical value and is not harmful for health. Therefore, repeated moderate cycling has an anti-inflammatory effect and may protect individuals from chronic disease. Changes in inflammatory indices in active (regularly exercise during the week) compared to nonactive (sedentary) individuals are small.

\section{Acknowledgments}

This study was supported by a grant from the Tuberculosis and Lung Disease Research Center, Tabriz University of Medical Science, Tabriz.

\section{Disclosure}

The authors report no conflicts of interest in this work.

\section{References}

1. Mathur N, Pedersen BK. Exercise as a mean to control low-grade systemic inflammation [review article]. Mediators of inflammation ID 10952. 2008:6 pages.

2. Abramson JL, Vaccarino V. Relationship between physical activity and inflammation among apparently healthy middle-aged and older US adults. Arch Intern Med. 2002;162:1286-1292.

3. Gleeson M. Immune functions in sport and exercise. $J$ Appl Physiol. 2007;103:693-699.

4. Reuben DB, Hamilton LJ, Harris TB, et al. The associations between physical activity and inflammatory markers in high-functioning older persons: MacArthur studies of successful aging. JAm Geriatr Soc. 2003; 51:1125-1130.

5. Nicklas BJ, You T, Pahor M. Behavioral treatment for chronic systemic inflammation: effects of dietary weight loss and exercise training. CMAJ. 2005;172:1199-1209.

6. Blake GJ, Ridker PM. Inflammatory bio-markers and cardiovascular risk prediction. J Intern Med. 2002;252:283-294.

7. Bruunsgard H. Physical activity and modulation of systemic low-level inflammation. J Leukoc Biol. 2005;78:819-835.
8. Thompson PD, Buchner D, Pina IL, et al. Exercise and physical activity in the prevention and treatment of atherosclerotic cardiovascular disease. Circulation. 2003;107:3109-3116.

9. Shaper AG, Wannamethee G, et al. Physical activity and ischemic heart disease in middle-aged British men. Br Heart J. 1991;66: 384-394.

10. Kasapis C, Thompson PD. The effect of physical activity on serum C-reactive protein and inflammatory markers. JACC. 2005;45: $1563-1569$

11. Geffken DF, Cushman M, Burke GL, et al. Association between physical activity and markers of inflammation in a healthy elderly population. Am J Epidemiol. 2001;153:242-250.

12. Petersen AMW, Pedersen BK. The anti-inflammatory effect of exercise. J Appl Physiol. 2005;98:1154-1162.

13. Markovitch D, Tarrell RM, Thompson D. Acute moderate-intensity exercise in middle-aged men has neither an anti- nor pro- inflammatory effect. J Appl Physiol. 2008;105:260-265.

14. Harris TB, Ferrucci L, Tracy RP, et al. Association of elevated in interleukin-6 and C-reactive protein levels with mortality in the elderly. Am J Med. 1999;106:506-512.

15. Hammett CJK, Prapavessis H, Baldi JC, et al. Effect of exercise training on 5 inflammatory markers associated with cardiovascular risk. $\mathrm{Am}$ Heart J. 2006;151:367e8-367e16.

16. Kondo N, Nomura M, Nakaya Y, et al. Association of inflammatory marker and highly sensitive $\mathrm{C}$-reactive protein with aerobic exercise capacity, maximum oxygen uptake and insulin resistance in healthy middle-aged volunteers. Circ J. 2005;69:452-457.

17. Church TS, Barlow CE, Earnest CP, et al. Associations between cardiorespiratory fitness and C-reactive protein in men. Arterioscler Thromb Vasc Biol. 2002;22:1869-1876.

18. Petersen AMW, Pedersen BK. The role of IL-6 in mediating the antiinflammatory effects of exercise. J Physiol Pharmacol.2006;57 Suppl 10 $43-51$.

19. Fisher CP, Berntsen A, Perstrup LB, et al. Plasma levels of interleukin-6 and C-reactive protein are associated with physical inactivity independent of obesity. J Med Sci. 2007;17:580-587.

20. Warburton DER, Nicol CW, Bredin SSD. Health benefits of physical activity: the evidence. CMAJ. 2006;174:801-809.

21. Hamer M, Stamatakis E. Physical activity and risk of cardiovascular disease events: inflammatory and metabolic mechanisms. Med Sci Sports Exerc. 2009;41:1206-1211.

22. Scharhag J, Meyer T, Gabriel HHW, et al. Does prolonged cycling of moderate intensity affect immune cell function? Br J Sports Med. 2005; 39:171-177.

23. Jankord R, Jemiolo B. Influence of physical activity on serum IL-6 and IL-10 levels in healthy older men. Med Sci Sports Exerc. 2004; 36:960-964. 
24. Peake JM, Suzuki K, Wilson G, et al. Exercise-induced muscle damage, plasma cytokines and markers of neutrophil activation. Med Sci Sports Exerc. 2005;37:737-745.

25. Steensberg JG, Ba A, Bregeon F, et al. Cytokine and oxidative responses to maximal cycling exercise in sedentary subjects. Med Sci Sports Exerc. 2007:39:964-968.

26. Starkie RL, Rolland J, Angus DJ, et al. Circulating monocytes are not the source of elevations in plasma IL-6 and TNF-alpha levels after prolonged running. Am J Physiol Cell Physiol. 2001;280: C769-C774.

27. Nieman DC, Henson DA, Austin MD, et al. Immune response to a 30-minute walk. Med Sci Sports Exerc. 2005;37:57-62.

28. Haskell WL, Lee IM, Pate RR, et al. Physical activity and public health: updated recommendation for adults from the American College of Sports Medicine and the American Heart Association. Med Sci Sports Exerc. 2007;39:1423-1434.

29. Jeurissen A, Bossuyt X, Ceuppensg L, et al. The effects of physical exercise on the immune system. Ned Tijdschr Geneeskd. 2003;147: 1347-1351.

30. Center for Disease Control and Prevention, National Center for Chronic Disease Prevention and Health Promotion. Physical activity and health: a report of the Surgeon General. Atlanta, GA: Department of Health and Human Services; 1996.

31. Zaldivar F, Wang-Rodriguez J, Nemet D, et al. Constitutive pro- and anti-inflammatory cytokine and growth factor response to exercise in leukocytes. J Appl Physiol. 2006;100:1124-1133.

32. Drela N, Kozdron E, Szczypiorski P. Moderate exercise may attenuate some aspects of immunosencence. BMC Geriatr. 2004;4:1-7.

33. Darren ERW, Crystal Whitney N, Shannon SD. Health benefits of physical activity: the evidence. CMAJ. 2006;174:801-809.
34. Gleeson M. Immune function in sport and exercise. J Appl Physiol. 2007;103:693-699.

35. Smith LL, Anwar A, Fragen M, et al. Cytokines and cell adhesion molecules associated with high-intensity eccentric exercise. Eur J Appl Physiol. 2000;82:61-67.

36. Plaisance EP, Taylor JK, Alhassan S, et al. Cardiovascular fitness and vascular inflammatory markers after acute aerobic exercise. Int J Sport Nutr Exerc Metab. 2007;17:152-162.

37. Robson APJ, Blannin A, Gleeson M. Elevated plasma interleukin-6 levels in trained male triathletes following an acute period of intense interval training. Eur J Appl Physiol. 2007;99:353-360.

38. Silveira EMS, Rodrigues MF, Krause MS, et al. Acute exercise stimulates macrophage function: possible role of NF-KB pathways. Cell Biochem Funct. 2007;25:63-73.

39. Pedersen BK, Rohde T, Ostrowski K. Recovery of the immune system after exercise. Acta Physiol Scand. 1998;99:325-332.

40. Brown RD. Aerobic exercise programming. In: Larry Durstine J, et al. editor. Resource Manual for Guidelines for Exercise Testing and Prescription 2nd ed. Philadelphia: Lea \& Febiger; 1993:344-349.

41. Heyward VM. Advanced Fitness Assessment and Exercise Prescription. 2nd ed. Human Champaign: Human kinetics; 1999:17-69.

42. Dill DB, Costill DL. Calculation of percentage changes in volumes of blood, plasma, and red cells in dehydration. J Appl Physiol. 1974;37: 247-248.

43. Cox AJ, Pyne DB, Gleeson M, Callister R. Relationship between C-reactive protein concentration and cytokine responses to exercise in healthy and illness-prone runners. Eur J Appl Physiol. 2009;107:611-614.

44. Jiménez R, Ramírez R, Carracedo J, et al. Cytometric bead array (CBA) for the measurement of cytokines in urine and plasma of patients undergoing renal rejection. Cytokine. 2005;32:45-50.
International Journal of General Medicine

\section{Publish your work in this journal}

The International Journal of General Medicine is an international, peer-reviewed open-access journal that focuses on general and internal medicine, pathogenesis, epidemiology, diagnosis, monitoring and treatment protocols. The journal is characterized by the rapid reporting of reviews, original research and clinical studies across all disease areas.

\section{Dovepress}

A key focus is the elucidation of disease processes and management protocols resulting in improved outcomes for the patient. The manuscript management system is completely online and includes a very quick and fair peer-review system. Visit http://www.dovepress.com/ testimonials.php to read real quotes from published authors. 